This is a postprint version of the following published document:

Fernández-Cañadas, L.M., Iváñez, I., \&

Sánchez-Sáez, S. (2016). Influence of the cohesive law shape on the composite adhesivelybonded patch repair behaviour. Composites Part $B, 91$, pp. 414-421.

DOI:10.1016j.compositesb.2016.01.056

(C) 2016 Elsevier Ltd. All rights reserved

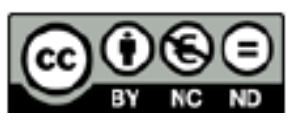

This work is licensed under a Creative Commons Attribution-NonCommercialNoDerivatives 4.0 International License. 


\title{
Influence of the cohesive law shape on the composite adhesively- bonded patch repair behaviour
}

\author{
Lorena M. Fernández-Cañadas, Inés Iváñez, Sonia Sanchez-Saez* \\ Department of Continuum Mechanics and Structural Analysis, University Carlos III of Madrid, Avda. de la Universidad 30, 28911 Leganés, Madrid, Spain
}

\section{A B S T R A C T}

In this study, the cohesive failure of the adhesive layer of an adhesively bonded joint under uniaxial tensile loads in static conditions is discussed as an approximation to the behaviour of adhesively bonded repairs. A three dimensional finite element model of a single lap joint was developed using the com mercial code Abaqus. Cohesive Zone Models (CZM) coupled to Finite Element Analysis, were used to study the failure strength of the joint. They allowed the prediction of the initiation of the crack and its growth. CZM are governed by a traction separation law, which can acquire different shapes. The nu merical model, considering a linear cohesive law, was validated with 2D numerical and experimental results available in the literature. The effect of different cohesive law shapes, such as exponential and trapezoidal, on the failure load of the joint was studied. In addition, a cohesive parametric analysis was performed, varying the adhesive toughness and cohesive strength. The most suitable cohesive law was the trapezoidal, since the failure load results were close to the experimental data taken from the liter ature. The cohesive strength is identified as the most influential parameter on the studied variable.

Keywords: Laminates, Adhesion, Fracture toughness, Finite element analysis (FEA), Cohesive zone model.

\section{Introduction}

Structural components made of composite materials are widely used in several fields, such as the aircraft industry, due to its excellent mechanical and lightness properties, representing a reduction in the weight and, consequently, lower fuel consumption. The high level of integration and large size of these components may make very difficult the replacement of damaged parts during its service life. The repair of the damaged components is an efficient solution that saves economic and temporal costs.

In contrast to mechanical repairs, adhesively bonded repairs offer certain advantages being the most suitable to thin laminates. In particular, patched repairs are more efficient than scarf repairs, which requires small bevel angles that result in additional damage when considering thin laminates [1]. Most repair techniques involve removing the damaged material, creating a hole, whose presence may modify the state of load on the structure, reducing the bearing capacity and fatigue life due to the appearance of stress concentration in the area near the hole. Thus, adhesively patch repairs are designed to minimise these stress concentrators

\footnotetext{
* Corresponding author. Tel.: +349162488 82 .

E-mail address: ssanchez@ing.uc3m.es (S. Sanchez-Saez).
}

without adding weight [2-4]. In addition, these repairs present non uniform shear and peeling stresses distributions inside the adhesive that give stress concentrations in the overlap edges [5], resulting that the adhesive failure is the main damage mechanism in a repaired plate. The overall failure of a repaired plate is sensitive to the adhesive properties and adhesive parameters related. Thus, it is important to perform parametric studies to determine the sensitivity of the repair behaviour to the damage evolution and the adhesive parameters selected [6]. Several authors have studied the behaviour of these repairs [7-10], being fewer who focus their efforts on analysing the influence of different parameters on the failure load [11,12].

Different methods are used to predict the stresses of an adhesive repair: analytical, numerical, and experimental $[5,13]$. In the last years, the use of progressive damage models, such as the Cohesive Zone Models (CZM) couple to Finite Element Analysis (FEA), was extended in front of Virtual Crack Closure Technique (VCCT) restricted to the Linear Elastic Fracture Mechanics (LEFM) which needs the existence of an initial crack [14-16]. CZM predict the onset of failure and its growth within regions of continuous ma terials or interfaces between different materials, resulting in more accurate results [5]. The crack growth is controlled by a traction separation law, being the linear, due to its simplicity, the expo nential, and the trapezoidal the most used [17-19]. 
Some authors approximate adhesively bonded repairs to single lap joints $[7,20]$. In this context, a detailed analysis of the critical parameters affecting the integrity of adhesive joints (i.e. geometry modifications, overlap length and adhesive properties) is needed. Recent research investigations on single lap joints formulate pre dictive equations considering thin laminates bonded to pre existing members, in order to study the collapse of the adhesive joint and optimal bonding length [21,22]. Many studies dealing with CZM [23] develop two dimensional finite element models to simplify the computational cost; however, an exhaustive analysis of the behaviour of a repair requires three dimensional models in order to obtain accurate results [13,24-27].

In the present work, a 3D numerical model was implemented by using Abaqus finite element code, which was validated with nu merical and experimental results extracted from the literature. The influence of the cohesive law shape (linear, exponential and trap ezoidal) and certain adhesive parameters (fracture toughness and cohesive strength) on the adhesively bonded single lap joint fail ure load was analysed, considering the cohesive failure of the adhesive.

\section{Problem description}

As a first approach to the study of the behaviour of adhesively bonded patch repairs, a single lap CFRP joint was analysed. To achieve this purpose, a three dimensional numerical model of an adhesively bonded single lap joint under uniaxial tensile loads in static conditions was developed by using the finite element code Abaqus/Standard [28], considering non linear effects.

The geometry considered consists of two laminates of unidi rectional carbon epoxy, $[0]_{16}$ lay up and a thickness for each lamina of $0.15 \mathrm{~mm}$, bonded with an epoxy adhesive, Araldite 2015 (Fig. 1). The total length between the two end edges is $\mathrm{L}_{t} 240 \mathrm{~mm}$, while its depth is b $15 \mathrm{~mm}$. The length of the bonded area $\mathrm{L}$ was modified for values from $10 \mathrm{~mm}$ to $80 \mathrm{~mm}$. The considered ge ometry was taken from the literature [29] in order to validate the proposed numerical model.

The main failure mechanism of a repaired structure is the ad hesive failure. Therefore, this work is focused on the study of the adhesive behaviour under tensile loads. In particular, the cohesive failure in the adhesive layer was analysed. Thus, the effect of the variation of several cohesive parameters on the maximum load, that causes the joint failure, was studied.

\subsection{Numerical model}

Each composite adherend was modelled as orthotropic, linear elastic (Table 1). The selected adhesive was modelled by using the mixed mode CZM formulation with a traction separation law (Table 2). The adhesive is characterised by a ductile behaviour due to the wide difference between the fracture toughness $G_{n}^{C}$ in the
Table 1

Elastic orthotropic properties of the adherend in the fibres direction [27].

\begin{tabular}{lllll}
\hline \multicolumn{2}{c}{ Elastic modulus [MPa] } & \multicolumn{2}{c}{ Poisson ratio } & \multicolumn{2}{c}{ Shear modulus [MPa] } \\
\hline $\mathrm{E}_{\mathrm{x}} \quad 10910^{3}$ & $v_{\mathrm{xy}}$ & 0.342 & $\mathrm{G}_{\mathrm{xy}}$ & 4315 \\
$\mathrm{E}_{\mathrm{y}} 8819$ & $v_{\mathrm{xz}}$ & 0.342 & $\mathrm{G}_{\mathrm{xz}}$ & 4315 \\
$\mathrm{E}_{\mathrm{z}} 8819$ & $v_{\mathrm{yz}}$ & 0.380 & $\mathrm{G}_{\mathrm{yz}}$ & 3200 \\
\hline
\end{tabular}

normal direction ( $\mathrm{x}$ axis) and $\mathrm{G}_{\mathrm{s}}^{\mathrm{C}}$ and $\mathrm{G}_{\mathrm{s}}^{\mathrm{C}}$ in the shear directions ( $\mathrm{y}$ and $\mathrm{z}$ axis, respectively).

The adhesive stiffness was defined as the ratio of the normal modulus (E) and shear modulus $(G)$ to its thickness (t), Eqs. (1) and (2)

$K_{n} \frac{E}{t}$

$K_{s} \quad K_{t} \quad \frac{G}{t}$

where $K_{n}, K_{s}$ and $K_{t}$ are the stiffness of the cohesive elements in the normal and shear directions.

To simulate the experimental test conditions, one of the edges was clamped, while the opposite end was pulled in tension by imposing a constant and uniform displacement through this end (Fig. 1). A sensitivity analysis was carried out to ensure that the model was capable of accurately calculating the stresses and associated deformations; as a result, the mesh of the adherends consisted of 75,000 eight node continuum shell elements with reduced integration (SC8R in Abaqus). For an overlap length of $10 \mathrm{~mm}$, the mesh of adhesive consisted of 3750 eight node three dimensional cohesive elements (COH3D8 in Abaqus) compatible with the previous elements used. In addition, a mesh refinement was applied nearby the bonded area, to obtain more accurate re sults in this zone (Fig. 2). The surface to surface contact interaction was used to define the contact between the composite plates and the adhesive.

\subsection{Progressive damage analysis}

CZM reproduce the adhesive behaviour in terms of cohesive traction separation response, in which different damage mecha nisms occur simultaneously. Each mechanism consists of a damage initiation, which depends on the criterion chosen, a damage evo lution that produces a stiffness reduction up to failure due to the progressive adhesive degradation, and the element removal when that failure is attained.

It is assumed that damage occurs in a local zone where the stress grows until a peak value $t_{n}^{0}$ in the normal direction and, $t_{s}^{0}$ and $t_{t}^{0}$ in shear directions, simulating the linear elastic behaviour. This behaviour is defined by a constitutive elastic matrix that relates the nominal stresses to the nominal strains across the interface, and can be written as follows in Eq. (3):

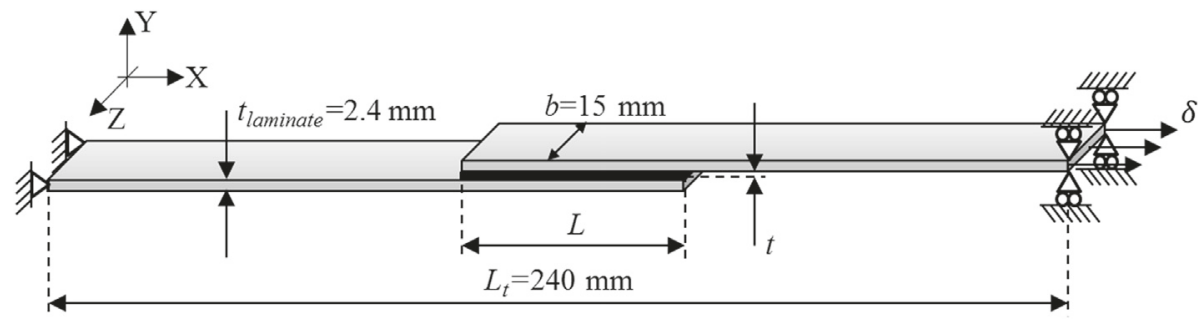

Fig. 1. Single-lap joint configuration: geometry and boundary conditions. 
Table 2

Adhesive properties of the Araldite 2015 for CZM modelling [27].

\begin{tabular}{|c|c|c|}
\hline Elastic and shear modulus [GPa] & Fracture toughness $[\mathrm{N} / \mathrm{mm}]$ & Cohesive strength [MPa] \\
\hline E 1.85 & 0.43 & 21.63 \\
\hline G $\quad 0.56$ & 4.70 & 17.90 \\
\hline & 4.70 & 17.90 \\
\hline
\end{tabular}

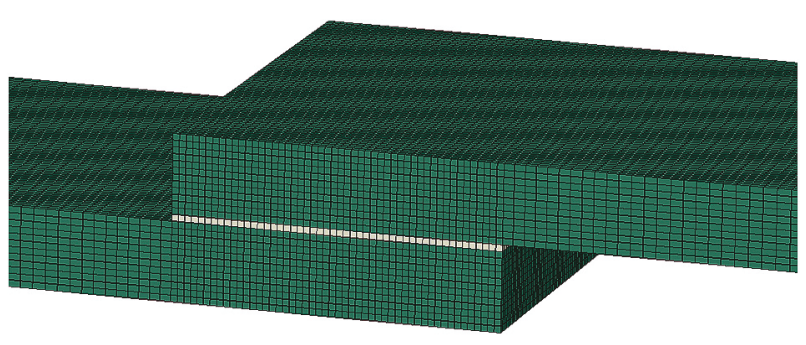

Fig. 2. Detail of the overlap length of $10 \mathrm{~mm}$ of the adhesively-bonded joint mesh.

$t \quad\left\{\begin{array}{l}t_{n} \\ t_{s} \\ t_{t}\end{array}\right\} \quad\left[\begin{array}{lll}K_{n n} & K_{n s} & K_{n t} \\ K_{n s} & K_{s s} & K_{s t} \\ K_{n t} & K_{s t} & K_{t t}\end{array}\right]\left\{\begin{array}{l}\varepsilon_{n} \\ \varepsilon_{s} \\ \varepsilon_{t}\end{array}\right\} \quad K \varepsilon$

where $t_{n}, t_{s}$ and $t_{t}$ are the traction stresses in the normal and shear directions respectively while $\varepsilon_{\mathrm{n}}, \varepsilon_{\mathrm{s}}$ and $\varepsilon_{\mathrm{t}}$ represent the strains in those same directions normal and shear. Meanwhile, $\mathrm{K}$ is the stiffness matrix related to the adhesive properties.

The damage initiation refers to the beginning of the degradation of the material when the stresses satisfy the chosen criterion. Some authors have investigated the effect of the interface failure criteria $[30,31]$ and several damage initiation criteria are available in Aba qus for cohesive elements. The criterion used in this work is the quadratic nominal stress criterion (QUADS) based on [32], which is given by Eq. (4):

$\left\{\frac{t_{n}}{t_{n}^{0}}\right\}^{2}+\left\{\frac{t_{s}}{t_{s}^{0}}\right\}^{2}+\left\{\frac{t_{t}}{t_{t}^{0}}\right\}^{2} \quad 1$

Once the damage initiation criterion is fulfilled, the material damage occurs according to a damage evolution law (Eq. (5)), which describes the rate at which the adhesive stiffness is degraded. A scalar damage variable $D$, that represents the overall damage in the adhesive, is defined. Initially, $D$ has a value of 0 , which implies that no damage has been occurred, and corresponds to the elastic region. After the initiation of the damage this value increases until 1 , when the material is fully damaged.

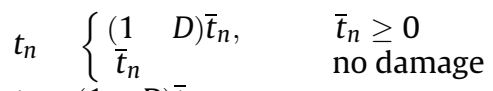

$$
\begin{aligned}
& \begin{array}{lll}
t_{s} & \left(\begin{array}{ll}
1 & D
\end{array}\right) \bar{t}_{s}
\end{array} \\
& \left.\begin{array}{lll}
t_{t} & (1 & D
\end{array}\right) \bar{t}_{t}
\end{aligned}
$$

where $\bar{t}_{n}, \bar{t}_{s}$ and $\bar{t}_{t}$ are the traction stresses in each direction pre dicted by the elastic traction separation behaviour without damage (Fig. 3).

In this work the influence of different shapes of damage evo lution was analysed and linear, exponential and trapezoidal laws were used (Fig. 4). For linear softening (Fig. 4a) the expression of the damage variable D is defined as follows in Eq. (6).
$D \frac{\delta_{m}^{f}\left(\begin{array}{ll}\delta_{m}^{\max } & \delta_{m}^{0}\end{array}\right)}{\delta_{m}^{\max }\left(\begin{array}{ll}\delta_{m}^{f} & \delta_{m}^{0}\end{array}\right)}$

where $\delta_{\mathrm{m}}^{\max }$ is the maximum value of the effective displacement achieved, and $\delta_{\mathrm{m}}^{0}$ and $\delta_{\mathrm{m}}^{\mathrm{f}}$ are the effective initial and final dis placements, respectively. These effective displacements can be calculated as shown in Eq. (7):

$\delta_{m} \quad \sqrt{\delta_{n}^{2}}+\delta_{s}^{2}+\delta_{t}^{2}$

The exponential softening (Fig. 4b) can be expressed as Eq. (8):

$D 1\left\{\frac{\delta_{m}^{0}}{\delta_{m}^{\max }}\right\}\left\{1 \frac{\left.\left.1 e^{-\alpha} \frac{\delta_{m}^{\max } \delta_{m}^{0}}{\delta_{m}^{f} \delta_{m}^{0}}\right)\right)}{1 e^{(-\alpha)}}\right\}$

where $\alpha$ is a non dimensional material parameter that defines the rate of damage. It is related to the specific material properties, and for $\alpha \quad 0$ the linear law is achieved. Different values for this variable have been taken in order to study its influence on the results. A value of $\alpha \quad 7$ was chosen to have a clearly distinction with the linear evolution and to be able to contrast the results with the available literature [29]. This choice means a faster degradation after the beginning of the damage. The trapezoidal law (Fig. 4c) takes the form in Eq. (9):

$\left\{\begin{array}{llll}D & 1 & \left\{\frac{\delta_{m}^{0}}{\delta_{m}}\right\} & \text { for } \delta_{m}^{0}<\delta \leq \delta_{m}^{S} \\ D & 1 & \left\{\frac{m \cdot \delta_{m}+b}{K_{n n, s s, t t} \cdot \delta_{m}}\right\} & \text { for } \text { si } \delta_{m}^{S}<\delta \leq \delta_{m}^{f}\end{array}\right.$

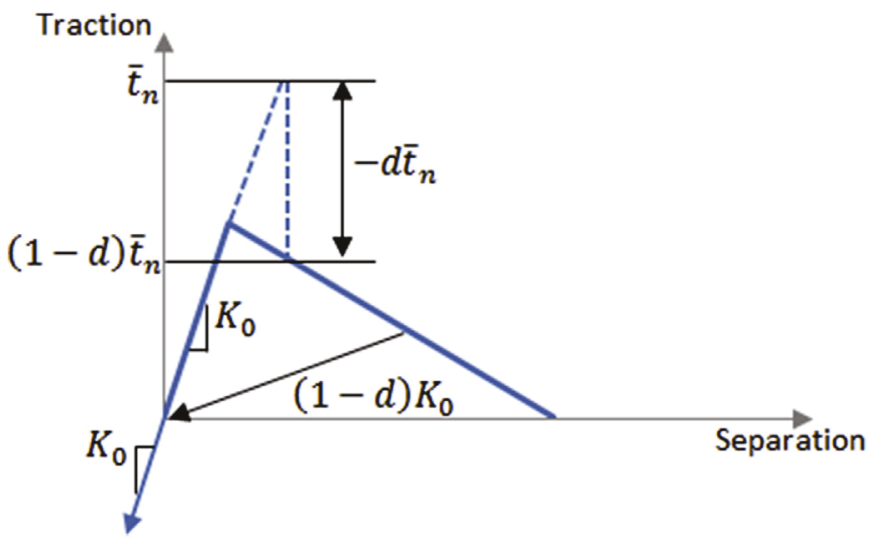

Fig. 3. Linear damage evolution law, extrapolable to the exponential and trapezoidal laws. 
a

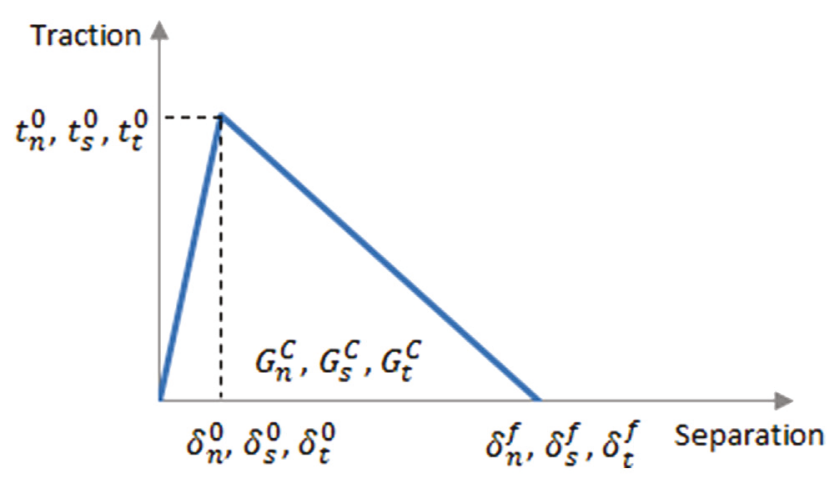

b

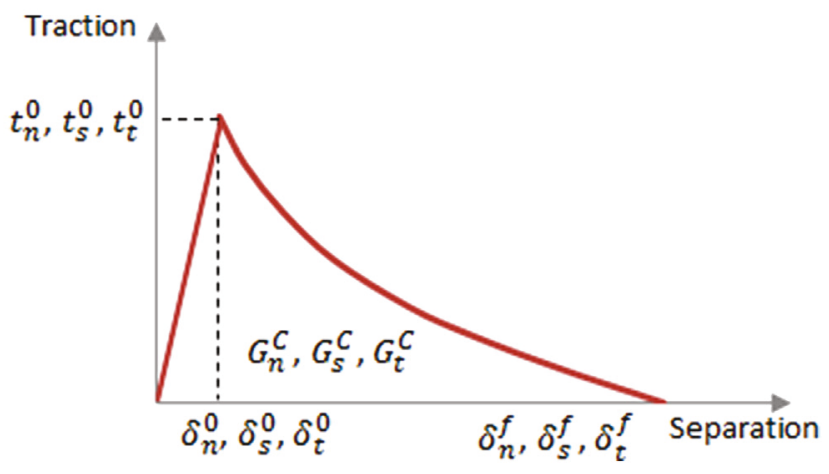

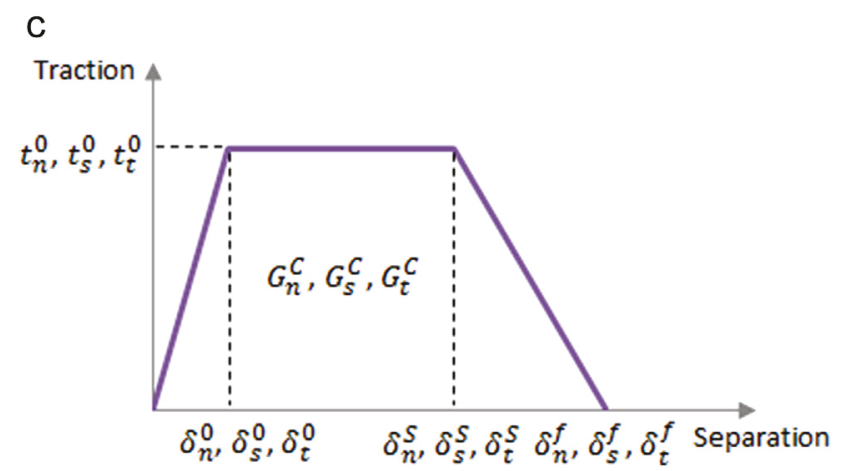

Fig. 4. Damage evolution laws considered: a) linear, b) exponential and c) trapezoidal.

where $\delta_{\mathrm{m}}^{\mathrm{S}}$ is the effective stress softening displacements, and $\mathrm{m}$ and $\mathrm{b}$ are parameters that determine the drop of the stress, and can be calculated as expressed in Eqs. (10) and (11):

$$
\begin{aligned}
& m \frac{t_{n, s, t}^{0}}{\delta_{m}^{f} \quad \delta_{m}^{S}} \\
& b \quad t_{n, s, t}^{0} \quad m \cdot \delta_{m}^{S}
\end{aligned}
$$

In this law, two regions can be differentiated: the first, where the stress maintains its value extending from $\delta_{\mathrm{m}}^{0}$ to $\delta_{\mathrm{m}}^{\mathrm{S}}$, and the second, where the stress value drops until it reaches 0 , extending from $\delta_{\mathrm{m}}^{S}$ to $\delta_{\mathrm{m}}^{\mathrm{f}}$.

\subsection{Model validation}

The 3D numerical model results were validated comparing with the experimental and 2D numerical data available in the literature [29]. The variable used in the validation was the load-displacement curve, which represents the behaviour of the adhesively bonded single lap joint under uniaxial tensile loads in static conditions. Results show two different regions: in a first stage, the load in creases linearly until a peak is reached. In the second stage, the damage begins to develop and the load value decrease as a result of the stiffness degradation of the adhesive until it reaches the com plete failure.

The results comparison is shown in Fig. 5 for two different overlap lengths $\mathrm{L}_{0} \quad 10 \mathrm{~mm}$ (Fig. 5a) and $\mathrm{L}_{0} \quad 80 \mathrm{~mm}$ (Fig. 5b) which allowed the comparison with results from Campilho et al. [29]. In both 2D and 3D models, the CZM linear law (Fig. 4a) was considered.

The numerical results obtained from the 3D model developed are in great agreement with both experimental and 2D numerical results taken from the literature. The maximum load value for $10 \mathrm{~mm}$ overlap length is $2.57 \mathrm{kN}$, while for $80 \mathrm{~mm}$ is $18.50 \mathrm{kN}$. These values are slightly higher regarding the $2 \mathrm{D}$ numerical results. The differences between them and the results from the literature (both numerical and experimental) are less than $5 \%$ in either case.

The effect of the variation of the cohesive parameters of the evolution law, such as adhesive toughness or cohesive strength, was validated. Results were analysed changing one of these pa rameters in the normal and shear directions, while keeping the other parameter unchanged. For both cohesive parameters, the reference values were varied from $80 \%$ to $+100 \%$ at constant in tervals of $20 \%$ (Fig. 6).

Results for overlap lengths of $\mathrm{L}_{0} \quad 10 \mathrm{~mm}$ and $\mathrm{L}_{0} \quad 80 \mathrm{~mm}$ were compared with the results from Campilho et al. [29] (Fig. 7).

The results show great agreement with the 2D numerical results taken from the literature. Variations on fracture toughness above the reference values, resulted in increments of the peak load that do not exceed $10 \%$ for the longest overlap studied ( $L_{0} \quad 80 \mathrm{~mm}$ ). Variations of this cohesive parameter below the reference value, resulted in a reduction of the failure load between $7 \%$ and $45 \%$ approximately. When decreasing the cohesive strength, the varia tions for the different overlaps were similar between them, and close to the variation of the cohesive parameter magnitude. In crements of this parameter resulted in large increases of the failure load, being higher with decreasing overlap length $(90.54 \%$ for $\left.\mathrm{L}_{0} \quad 10 \mathrm{~mm}\right)$.

\section{Results}

\subsection{Effect of the cohesive law shape}

The influence of the traction separation law shape on the tensile behaviour of the adhesively single lap joint was analysed. The 

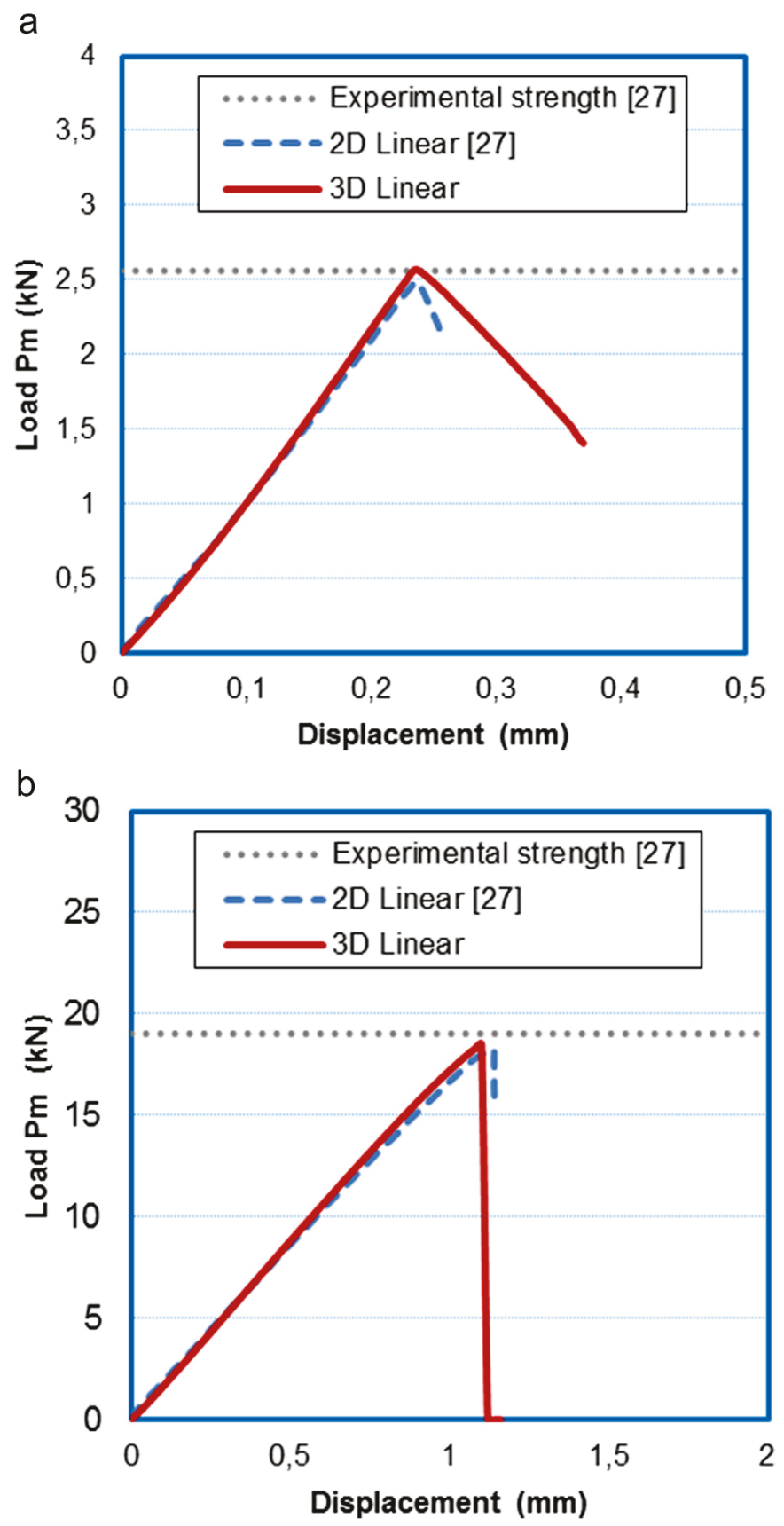

Fig. 5. Validation of the numerical model: load-displacement curves for overlaps lengths of a) $\mathrm{L}_{0} \quad 10 \mathrm{~mm}$ and b) $\mathrm{L}_{0} \quad 80 \mathrm{~mm}$.

obtained results, for the linear, exponential and trapezoidal cohe sive laws, have been compared with the experimental results of Campilho et al. [29] for different overlaps lengths, ranging between $10 \mathrm{~mm}$ and $80 \mathrm{~mm}$. Fig. 8 shows the percentage variations of the maximum load attained between the 3D numerical model results and the experimental data taken from the literature.

Results gave good predictions of failure load when compared with the experimental values, showing variations less than $\pm 7 \%$ for any cohesive law considered. The exponential law overestimated the maximum load for the full range of lengths analysed due to the delay in reaching the softening. Both linear and trapezoidal laws overestimated the maximum load for overlaps below $40 \mathrm{~mm}$; however, for overlaps above $40 \mathrm{~mm}$, this value was underestimated. Attending to these variations, the trapezoidal law presented the best fit to the experimental results as this law captures the plastic flow of the adhesive showing a ductile behaviour.

In addition, in order to analyse the role played by the width of the adherends (b) on the maximum failure load, numerical analysis for joints with half and double the reference width $7.5 \mathrm{~mm}$ and $30 \mathrm{mmm}$, respectively) were carried out using linear, exponential and trapezoidal cohesive laws. Results showed a directly propor tional relationship between failure load and width of the adher ends, presenting differences below $5 \%$.

\subsection{Variation of cohesive parameters of the cohesive law}

In order to study the influence of the damage evolution law on the failure load of the joint, two cohesive parameter values (frac ture toughness and cohesive strength) for different overlap lengths (10 mm, $30 \mathrm{~mm}, 60 \mathrm{~mm}$ and $80 \mathrm{~mm}$ ) were changed. Particularly, the exponential and trapezoidal CZM laws were considered. All results have been presented in percentage variations, as the ratio of the maximum load attained for the modified cohesive parameter to the maximum load for the reference case with the original cohesive parameters.

\subsubsection{Effect of the variation of cohesive parameters of the exponential law}

The effect of the variation of cohesive parameters of the expo nential law (Fig. 4b) was studied varying the fracture toughness and the cohesive strength by $50 \%,+50 \%$ and $+100 \%$ separately (Fig. 9 ), and for four different overlap lengths. The studied parameters have been modified in both normal and shear directions.

The percentage variations when changing each cohesive parameter for the different overlaps, are shown if Fig. 10. The ten dency was the same for both parameters regarding the results obtained when validating the linear law, but the variations when studying the fracture toughness were lower. When increasing or decreasing the fracture toughness (Fig. 10a), the higher variations that are found in the maximum load are less than $+6 \%$ and $10 \%$ respectively, which correspond to the longest overlap results. Thus, changes on this parameter do not cause significantly variations on the failure load.

When changing the cohesive strength (Fig. 10b), the highest variations occurred for the shortest overlap ( $\mathrm{L}_{0} 10 \mathrm{~mm}$ ), that vary in a linear manner in the different cases considered, from $49.55 \%$ to $+93.05 \%$. These variations are similar to the percentage variation of the cohesive strength. Decrements of this parameter, caused the same effect on the different overlap lengths. Increments caused significant variations, but not as noticeable as those observed for $10 \mathrm{~mm}$ overlap. For $\mathrm{L}_{0} \quad 80 \mathrm{~mm}$, the variations when increasing the cohesive strength $+50 \%$ and $+100 \%$, are very close $(+35.51 \%$ and $+38.87 \%$ respectively). Thus, the effect on the failure load of increasing this parameter above $+50 \%$ is reduced with the incre ment of the overlap length.

\subsubsection{Effect of the variation of cohesive parameters of the trapezoidal law}

As presented in the previous section, the fracture toughness and cohesive strength were varied by $50 \%,+50 \%$ and $+100 \%$ sepa rately (Fig. 11) and for the same overlap lengths.

Fig. 12 shows the results for the trapezoidal law. The variations on the maximum load are smaller than $+2 \%$ when increasing the fracture toughness (Fig. 12a). Only the longest overlap presented a more significant variation ( $15.38 \%$ ) when the cohesive parameter decreased by $50 \%$. In this case, the maximum shear stresses are higher, resulting in the reduction of the maximum load due to the cohesive failure. 


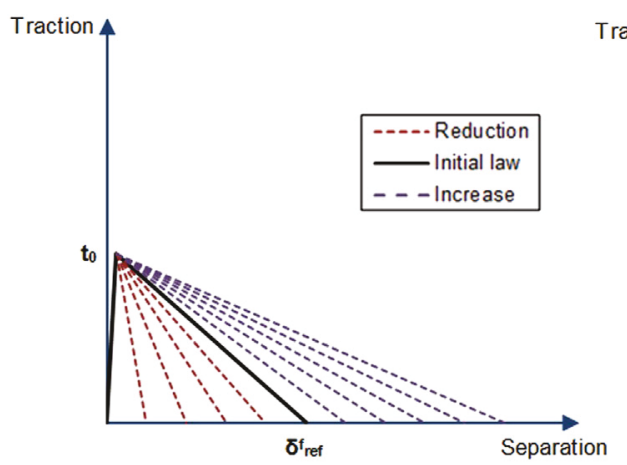

a)

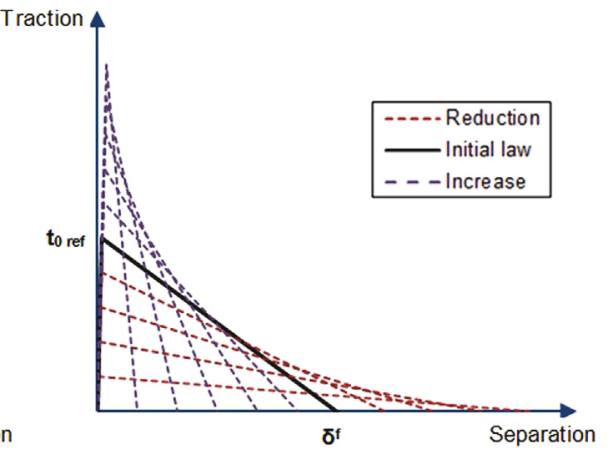

b)

Fig. 6. Cohesive linear law: variation of the a) adhesive toughness and b) cohesive strength (Applicable on the normal and shear directions).

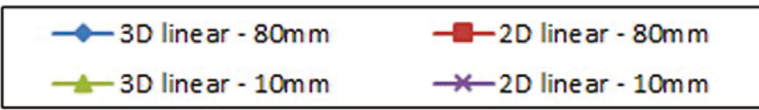

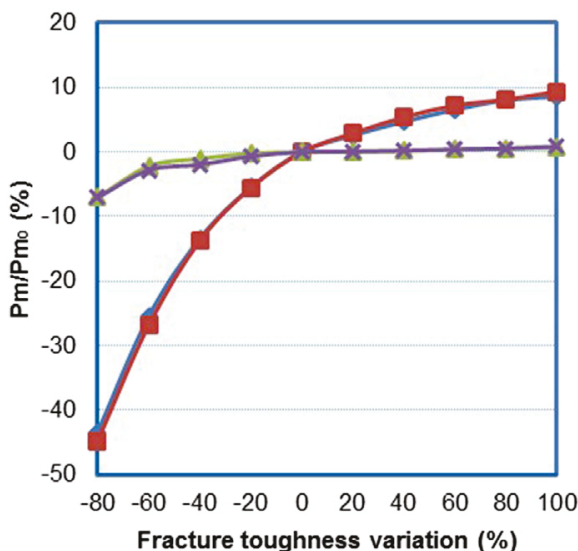

a)

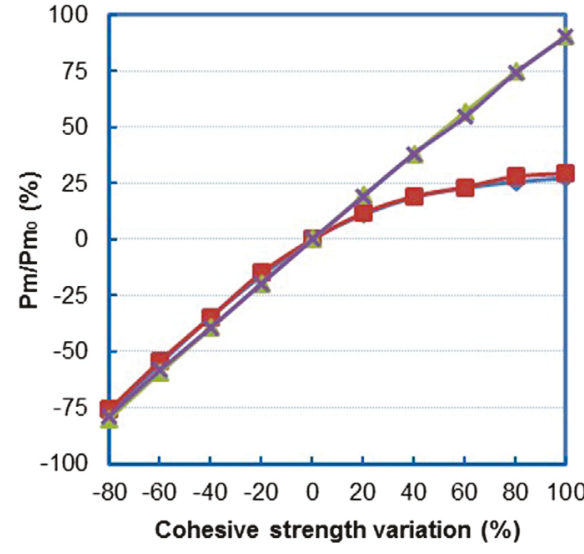

b)

Fig. 7. Linear law: effects of the variation of the cohesive parameters for overlap lengths of $\mathrm{L}_{0} \quad 10 \mathrm{~mm}$ and $\mathrm{L}_{0} \quad 80 \mathrm{~mm}$ :a) fracture toughness and b) cohesive strength.

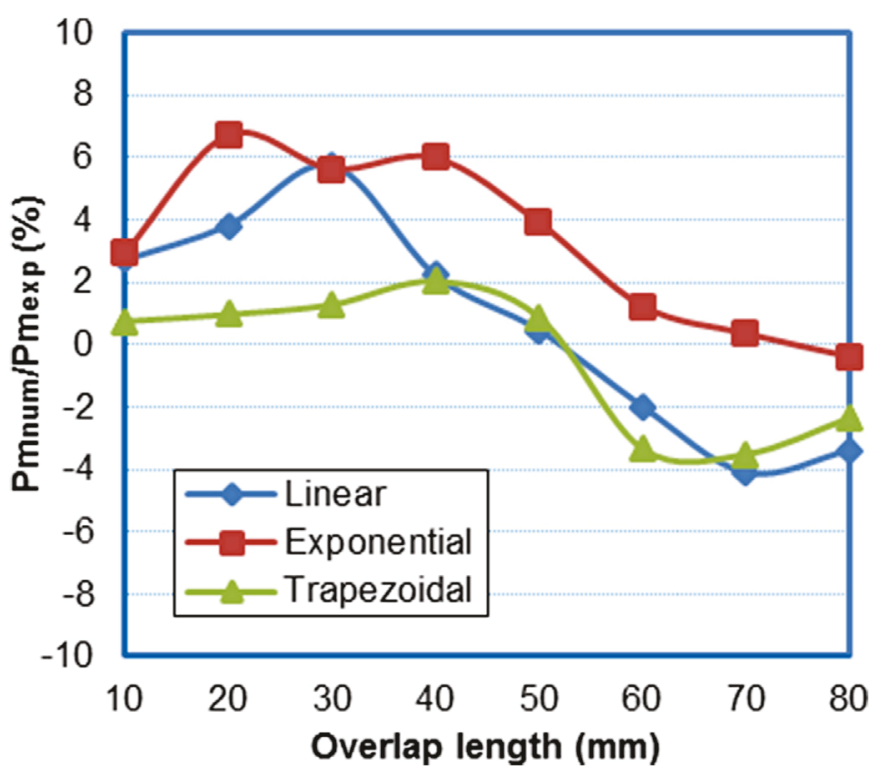

Fig. 8. Percentage variation between the $3 \mathrm{D}$ numerical results and the experimental results [27] for the different traction-separation laws.
A diminution of the cohesive strength (Fig. 12b) caused re ductions on the failure load, between a $30 \%$ and $37 \%$ for the overlap lengths studied, except for $\mathrm{L}_{0} \quad 10 \mathrm{~mm}$. With increasing cohesive strength, higher variations occurred for the shortest overlaps ( $\mathrm{L}_{0} \quad 10 \mathrm{~mm}$ and $\mathrm{L}_{0} \quad 30 \mathrm{~mm}$ ), in which the variations keep increasing. However, for longest overlaps $\left(\mathrm{L}_{0} \quad 60 \mathrm{~mm}\right.$ and $\mathrm{L}_{0} \quad 80 \mathrm{~mm}$ ) increasing the cohesive strength by $+100 \%$, produces a decrement, about $1 \%$ and $3 \%$ respectively, in the maximum load regarding to results with cohesive strength by $+50 \%$. This fact is due to the similarity of the modified trapezoidal law to an equivalent linear law, with the same cohesive strength and final relative displacement. Consequently, the fracture toughness of the equiva lent linear law is lower but, as stated in previous sections, this change does not result in significant variations. Thus, for overlap length above $40 \mathrm{~mm}$, the variation of the cohesive strength does not describe the plastic flow inside the adhesive, since the second part of the curve (where the stresses are constant) is shorter than the reference law.

\section{Conclusions}

In this work, the influence of the damage evolution law shape and cohesive parameters, for different overlap lengths, on the behaviour of an adhesively single lap joint under 


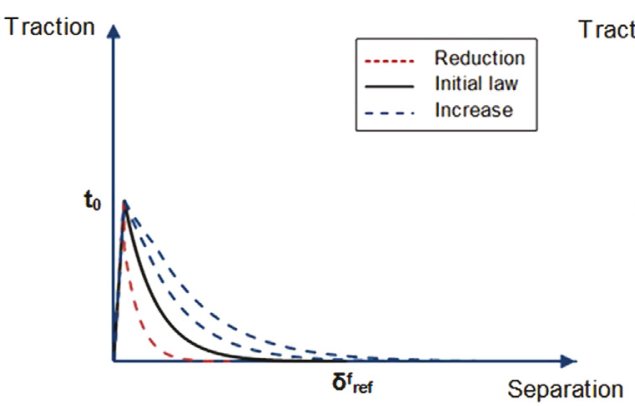

a)

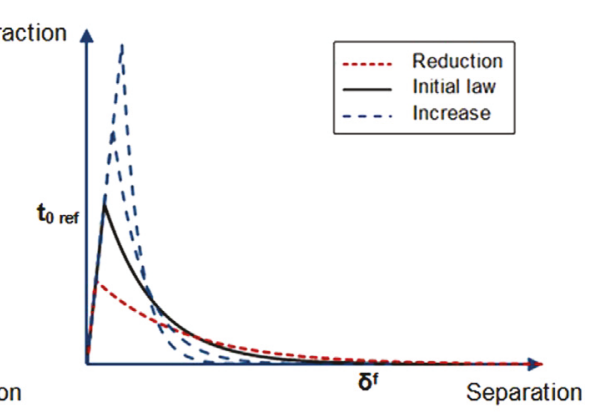

b)

Fig. 9. Cohesive exponential law: variation of the a) adhesive toughness and b) cohesive strength (Applicable on the normal and shear directions).

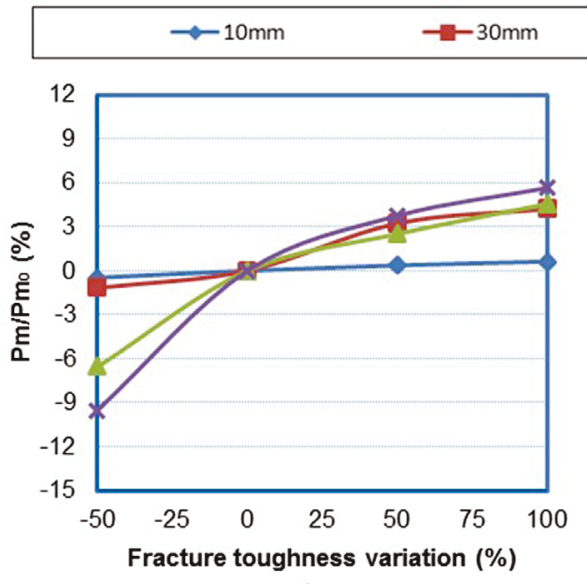

a)

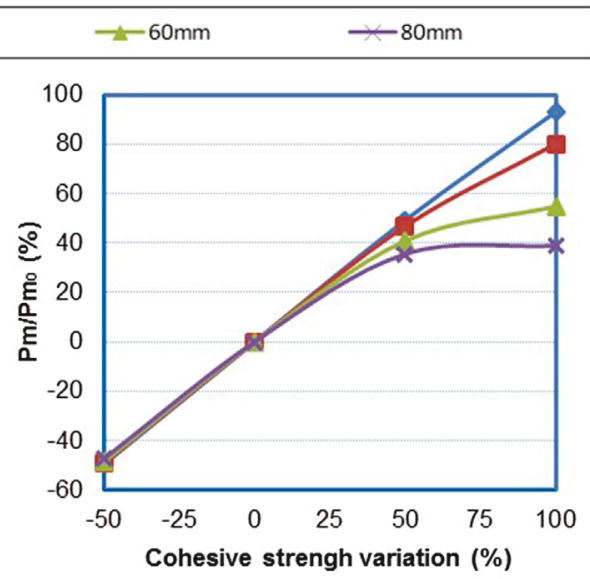

b)

Fig. 10. Exponential law: effects of the variation of cohesive parameters on the failure load changing a) the fracture toughness and b) the cohesive strength.

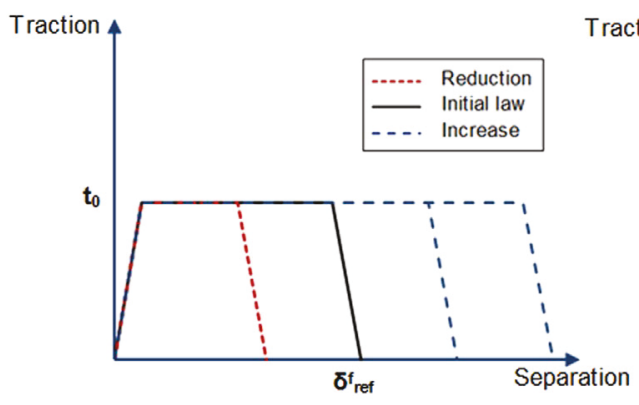

a)

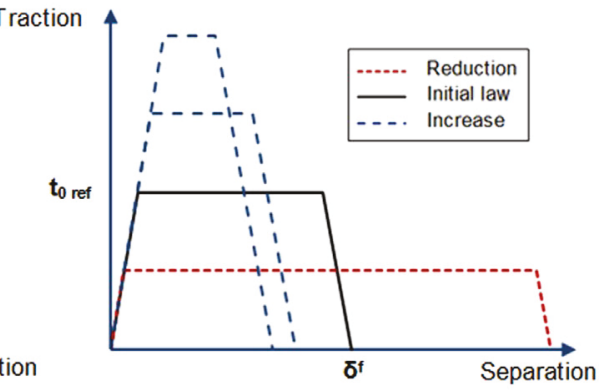

b)

Fig. 11. Cohesive trapezoidal law: variation of the a) adhesive toughness and b) cohesive strength (applicable on the normal and shear directions).

uniaxial tensile loads in static conditions was analysed. Virtual tensile tests varying the fracture toughness and cohesive strength were performed by developing a numerical model using Abaqus/Standard validated with available results in the literature.

The 3D numerical model developed reproduces the behaviour of the joint with high accuracy regarding to the results of the litera ture. Maximum load values of the 3D numerical model were higher than the obtained by Campilho et al. [29] in their 2D numerical model, and therefore more conservative. The different cohesive laws studied showed differences below the $\pm 7 \%$ in any case. The exponential law overestimated the failure load for all overlap length. The linear and trapezoidal laws overestimated the maximum load for overlaps less than $40 \mathrm{~mm}$ while underestimated for overlaps greater than $40 \mathrm{~mm}$.

The adhesive considered is a ductile adhesive that showed a large plastic flow. The trapezoidal law captured this behaviour, presenting closer results to the experimental ones, than the others laws. Thereby, it is important to use a suitable cohesive law shape according to the adhesive employed and its behaviour.

The parametric study showed that the maximum load is sensi tive to both cohesive parameters considered, fracture toughness and cohesive strength. However, this failure load is more sensitive to the cohesive strength than to the fracture toughness when using any of the cohesive laws studied. Highest variations for the fracture toughness occurred for the longest overlaps. Linear and 


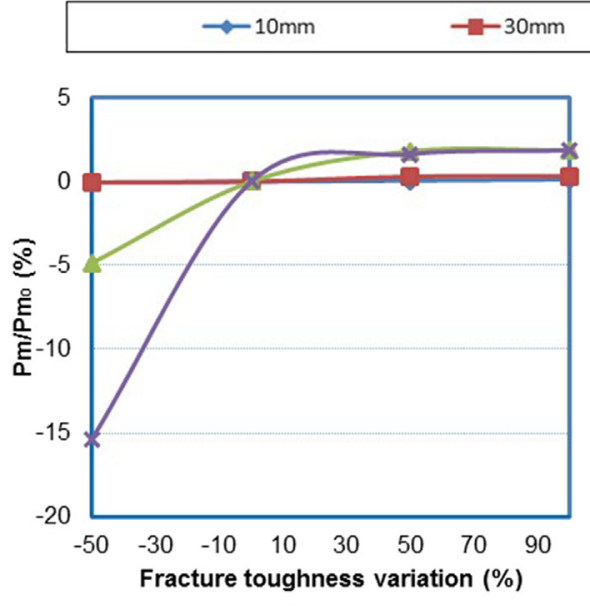

a)

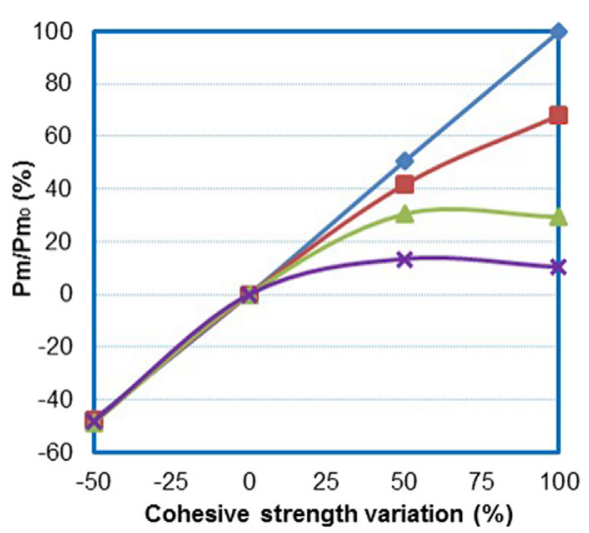

b)

Fig. 12. Trapezoidal law: effects of the variation of cohesive parameters on the failure load changing a) the fracture toughness and b) the cohesive strength.

exponential cohesive laws presented a similar behaviour when varying these cohesive parameters, although the exponential law resulted in high variations for the longest overlaps when increasing the cohesive strength due to the delay of the adhesive softening ( $\sim 25 \%$ for the linear, which underestimated the load, and $\sim+40 \%$ for the exponential, which overestimated the load). The trapezoidal law presented variations below the maximum reference load ( 8\%) due to the similarity of the modified law to an equivalent linear law, since the constant stress section is very short and do not capture the plastic flow in the adhesive.

\section{Acknowledgment}

The authors are indebted for the financial support of this work to the Ministry of Economy and Competitiveness of Spain (project DPI2013 42240 R).

\section{References}

[1] Zimmerman KB, Liu D. An experimental investigation of composite repair. Exp Mech 1996;36:142 7 .

[2] He X. A review of finite element analysis in adhesively bonded joints. Int J Adhesion Adhesives 2011;31:248 64 .

[3] Rachid M, Serier B, Bachir B, Belhouari M. Numerical analysis of the patch shape effects on the performances of bonded composite repair in aircraft structures. Compos Part B 2012;43:391 7.

[4] Chue C, Liu T. The effects of laminated composite patch with different stacking sequences on bonded repair. Compos Part B 1995;2:223 30.

[5] Banea MD, Da Silva LFM. Adhesively bonded joints in composite materials: an overview. Proc Institution Mech Eng Part L J Mater Des Appl 2009;223(1): 118.

[6] Ridha M, Tan VBC, Tay TE. Traction-separation laws for progressive failure of bonded scarf repair of composite panel. Compos Struct 2011;93:1239 45

[7] Campilho RDSG, de Moura MFSF, Domingues JJMS. Modelling single and doublelap repairs on composite materials. Compos Sci Technol 2005;65:1948 58.

[8] Liu X, Wang G. Progressive failure analysis of bonded composite repairs. Compos Struct 2007;81:331 40.

[9] Caminero MA, Pavlopoulou S, Lopez-Pedrosa M, Nicolaisson BG, Pinna C, Soutis C. Analysis of adhesively bonded repairs in composites: damage detection and prognosis. Compos Struct 2013;95:500 17.

10 Benyahia F, Albedah A, Bouiadjra B. Analysis of the adhesive damage for different patch shapes in bonded composite repair of aircraft structures. Mater Des 2014;54:18 24 .

[11] Alfano G. On the influence of the shape of the interface law on the application of cohesive-zone models. Compos Sci Technol 2006;66:723 30.

[12] Seong M-S, Kim T-H, Nguyen K-H, Kwepn J-H, Choi J-H. A parametric study on the failure of bonded-single-lap joints of carbon composite and aluminium. Compos Struct 2008;86:135 45 .
[13] Kim KS, Yoo JS, Yi YM, Kim CG. Failure mode and strength of uni-directional composite single lap bonded joints with different bonding methods. Compos Struct 2006;72:477 85

[14] Pirondi A, Giuliese G, Moroni F, Bernasconi A, Jamil A. Comparative study of cohesive zone and virtual crack closure techniques for three-dimensional fatigue debonding. J Adhesion 2014;90:457 81

[15] Panigrahi SK, Pradhan B. Three dimensional failure analysis and damage propagation behaviour of adhesively bonded single lap joints in laminated FRP composites. J Reinf Plast Compos 2007;26(2):183 201.

[16] Floros IS, Tserpes KI, Lobel T. Mode-I, mode-II and mixed mode I+II fracture behaviour of composite bonded joints: experimental characterization and numerical simulation. Compos Part B 2015;78:459 68.

[17] Shet C, Chandra N. Effect of the shape of T- $\delta$ cohesive zone curves on the fracture response. Mech Adv Mater Struct 2004:11:249 75 .

[18] Castro J, Keller T. Ductile double-lap joints from brittle GFRP laminates and ductile adhesives, part I: experimental investigation. Compos Part B 2008;39(2):271 81.

[19] Li G, Li C. Assessment of debond simulation and cohesive zone length in a bonded composite joint. Compos Part B 2015;69:359 68

[20] Costa J, Renart J, Batista Y, Mahdi S, Rodriguez-Bellido A. Detailed investigation of bonded joints for composite repairs. In: 18th international conference on composite materials; 2011.

[21] Ascione F, Mancusi G. Curve adhesive joints. Compos Struct 2012;94: 265764.

[22] Mancusi G, Ascione F. Performance at collapse of adhesive bonding. Compos Struct 2013;96:1 6 .

[23] Campilho RDSG, Banea MD, Neto JABP, da Silva LFM. Modelling of single-lap joints using cohesive zone models: effect cohesive parameters on the output simulation. J Adhesion 2012;88:513 33.

[24] Gonçalves JPM, de Moura MFSF, de Castro PMST. A three-dimensional finite element model for stress analysis of adhesive joints. Int J Adhesion Adhesives 2002;22:357 65 .

[25] Kim KS, Yi YM, Cho GR, Kim CG. Failure prediction and strength improvement of uni-directional composite single lap bonded joints. Compos Struct 2008:82(4):513 20.

[26] Ozel A, Yazici B, Akpinar S, Aydin MD, Temiz S. A study on strength of adhesively bonded joints with different adherends. Compos Part B 2014;62: $167 \quad 74$

[27] Li J, Yan Y, Zhang T, Liang Z. Experimental study of adhesively bonded CFRP joints subjected $95 \quad 104$

[28] Hibbit, Karlsson, Sorensen. Abaqus user's manual, Pawtucket, Rhode, Island. 2012.

[29] Campilho RDSG, Banea MD, Neto JABP, da Silva LFM. Modelling adhesive joints with cohesive zone models: effect of the cohesive law shape of the adhesive layer. Int J Adhesion Adhesives 2013;44:48 56.

[30] Ascione F, Mancusi G. Failure criteria for FRP adhesive lap joints: a comparative analysis. Mech Adv Mater Struct 2010;17:157 64.

[31] Camanho PP, Davila CG. Mixed-mode decohesion finite elements for the simulation of delamination in composite materials. 2002. p. 1 37. NASA/TM2002-211737.

[32] Hutchinson JW, Suo Z. Mixed-mode cracking in layered materials. Adv Appl Mech 1992;29:63 191 